\title{
Emergence of a Bilingual Grammar: Word Order Differences in Monolingual Basque vs. Bilingual Basque-Spanish Predicative Constructions
}

\author{
Hanna Lantto \\ University Lecturer of Spanish, School of Languages and \\ Translation, University of Turku, Turku, Finland \\ hanna.lantto@utu.fi
}

\begin{abstract}
This article compares the monolingual Basque predicative constructions with bilingual Basque-Spanish predicative constructions. The speech data for the study were collected in the Greater Bilbao area of the Basque Country between 2005 and 2012. The results suggest that code-switching may trigger the convergence of predicative constructions and have a significant impact on the general word order patterns. The monolingual predicative constructions in the data mostly follow the canonical Basque sXv word order $(\sim 81 \%)$, but the bilingual predicative constructions diverge from this word order in that the predicative element is located in a post-verbal position, as in Spanish $(\sim 8 \circ \%)$. The Spanish lexical elements seem to be strongly associated with the corresponding Spanish construction, the word order of which is then applied to otherwise Basque predicative constructions. I explain the predominance of the Spanish word order in the bilingual constructions by a combination of processingrelated factors and sociolinguistic factors.
\end{abstract}

\section{Keywords}

Basque - Spanish - predicative constructions - convergence 


\section{Introduction}

In the towns, fishing villages and mountain valleys of the Basque Country, the speakers of the language isolate known as euskara, Basque, have shared space and linguistic resources with the speakers of vulgar Latin and its descendants for the last two thousand years. The survival of the Basque language in an environment where all the other pre-Romance and even pre-Indoeuropean languages have become extinct is often considered to be an exceptional occurrence. Nevertheless, the long-lasting language contact has left its traces in the language spoken by the Basques: extensive lexical and structural borrowing from Latin, Romance and Castilian Spanish to Basque has been continuous throughout their joint history. Basque has been (and still is) the minority language in the area, not always in numerical terms, but in terms of institutional power that has been in the hands of the non-Basque speakers. Therefore, the bilingualism in the Basque Country has been traditionally unidirectional. The Basque speakers have had to learn Spanish in order to lead their daily lives, whereas the Spanish speakers have had no need or motivation to learn Basque. However, this has been changing during the last forty years, since Spain transitioned from a Spanish nationalist dictatorship with oppressive language policies towards the minority languages to a democracy, and Basque became a co-official language with Spanish in the Basque Autonomous Community. The Basque Country welcomed a new era of language revitalization, which has led to more mutual patterns of second language learning. Particularly in city areas the number of bilingual speakers of Basque and Spanish who have Spanish as their first language now outnumber the native Basque speakers (Basque Government, 2009: 72).

All Basque speakers today are virtually bilingual after their early childhood, and extensive code-switching and borrowing between Spanish and Basque can be observed throughout the Basque Country. Basque is often spoken in bilingual mode (Grosjean, 1997) The constructions labelled "Basque" and "Spanish" of the bilingual's repertoire do not need to be strictly separated for the Basque speaker to be understood. Both can be activated at the moment of linguistic production, unless the speaker feels the need to suppress one set of constructions. They are still both activated to some degree.

The languages are typologically different. Basque is an agglutinating sov language with an ergative-absolutive system, rich inflectional morphology and a complex auxiliary verb system, whereas Spanish is a mainly fusional Romance language with prepositions, and an svo word order. Despite this typological distance, Basque has developed shared constructions with Spanish throughout the centuries of co-existence in the same area. Large parts of 
Basque phraseology, lexical conceptual structure and lexical connotations have been modelled on the dominant language of the area, Spanish. During the centuries, many of these patterns have become conventionalized ${ }^{1}$ to such a degree that their similarity might be visible only for a person coming from another linguistic environment. Most importantly, mutual interference is an ongoing, emergent linguistic phenomenon that can be observed in the everyday speech of the bilinguals in the Basque Country.

This article compares the word order of Basque-Spanish bilingual predicative constructions with the word order of monolingual Basque predicative constructions. The main research question that I ask is how does code-switching of one word within the predicative construction affect the word order of the construction? In copular sentences, the Basque predicative construction could be described as [PRED V], whereas its counterpart in Spanish is [V PRED]. They exhibit opposite word orders. We could, therefore, expect there to be a clash when Spanish predicatives are used within Basque structures in bilingual speech production. The word orders of both predicative constructions are represented in the bilingual mind. The speakers' past interactional experiences are reflected in their language use, and their ongoing production is shaped by the need to conform with the current interactional situation (Beckner et al., 20o9; Riionheimo and Frick, 2014). The speakers do not only have previous linguistic knowledge of the abstract schematic form of predicative constructions, but also of the words within them. The particular words and constructions that function as predicative elements within these constructions carry with them all the instances of their previous use.

The typological distance of Basque and Spanish does not usually allow for an easy comparison of syntactic phenomena. Yet a comparison of monolingual predicative constructions and bilingual constructions with a Spanish predicative is particularly yielding because the impact of other structural features is minimal. The structural similarity of these constructions allows the speakers to easily detect interlingual connections and find analogies between the elements that comprise the construction. In both languages, the construction consists of a copula verb and a predicative element (and sometimes a subject in nominative/absolutive, morphologically "unmarked" case).

1 I follow the suggestion made by Backus (2014) and reserve the term 'conventionalization' for the community/social level and 'entrenchment' for the individual level of language change. When a linguistic construction becomes more integrated into the cognitive representation of an individual, it becomes more entrenched. When the construction becomes more frequent at the community level, it becomes more conventionalized. 
Basque: [Predicative element copULA] (Hereafter XV)

Spanish: [Copula Predicative element] (Hereafter vx)

Only the constructions with the Basque $d a$ (third person singular of the verb izan 'to be') are examined to keep the comparison as simple as possible. Furthermore, only predicative structures of affirmative sentences will be considered, as the Basque word order in negative clauses changes to (S)VX and the word order contrast between the languages is thus lost. The only distinctive feature between the monolingual and bilingual constructions examined in this study is the insertion vs. non-insertion of a Spanish predicative element.

The structure of the paper is as follows: section 2 will outline the work on Basque word order and predicative constructions as found in both prescriptive and descriptive grammars, followed by a brief description of the Spanish syntax and word order. Section 3 will present the data that this study is based on, and a synopsis of the main findings. Finally,section 4 discusses the implications of the results and interprets them in the light of the usage-based framework. The usage-based approach allows an interpretation in which sociolinguistic factors and grammar are deeply intertwined in the outcome of language contact, as social factors are "a part of the cognitive processes whose end product we understand as grammar(s)" (Babel and Pfänder, 2014).

\section{Predicative Constructions in Basque and Spanish}

\subsection{Word Order of Predicative Constructions in Basque}

Basque is generally described as having a canonical sov word order. However, due to the rich morphology of the language, the object can be used both preand postverbally, and the word order varies easily according to the information structure of the sentence. A strong grammatical tradition suggests that the Basque word order is free apart from the location of $w h$-words and foci, which are always to be left-adjacent to the verb (Hualde and Ortiz de Urbina, 1993: 13). Arregi (2001: 1) notes that one of the most studied syntactic properties in Basque is its obligatory pre-verbal focus position. This strong tendency can be exemplified with question-answer pairs, where the need to locate the focus in a pre-verbal focus position can result in an Osv word order as opposed to the canonical sov word order. In both the question and the answer, the focused constituent (the question word and the answer to the question) are located in a pre-verbal position. The following examples (2-6) illustrating this usage in the Ondarroa Basque dialect are from Arregi (2001:1). The focused elements of the examples are underlined throughout the article. 


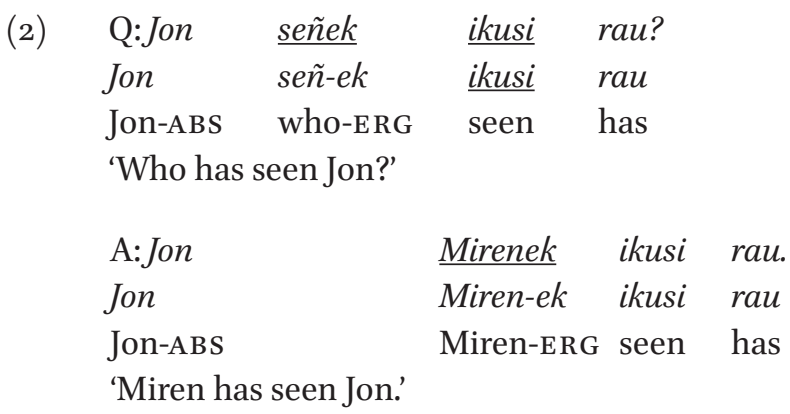

Euskal gramatika osoa 'The full Basque grammar' describes Basque as having an unmarked subject-component-verb word order, in which the verb is located at the end of the sentence. This word order in Spanish or French, the closest referents, would be "not only unusual, but erroneous" (Zubiri and Zubiri, 200o: 623-624). Yet the grammar books also note that the word order in Basque is relatively free. Even a three-word sentence such as Jon etxean dago 'Jon is (at) home' can be formulated in several different ways, such as sentences $3^{-6}$ :

$\begin{array}{lll}\text { (3) Jon } & \underline{\text { etxean }} & \text { dago. } \\ \text { Jon } & \text { etxe-an } & \text { dago. } \\ \text { Jon-ABs } & \text { home/house-INESS } & \text { cop } \\ \text { 'Jon is (at) home.' } & \end{array}$

$\begin{array}{lll}\text { (4) } & \text { dago } & \begin{array}{l}\text { etxean. } \\ \text { Jon-ABS }\end{array} \\ \text { COP } & \text { home }\end{array}$

$\begin{array}{lll}\text { (5) Etxean } & \text { Jon } & \text { dago. } \\ \text { Home-INESS } & \text { Jon-ABs } & \text { COP }\end{array}$

(6) $\begin{array}{ll}\text { Etxean } & \text { dago Jon. } \\ \text { Home-INESS } & \text { COP Jon-ABS }\end{array}$

(Zubiri and Zubiri, 2000: 623)

All these word orders are grammatical, yet the short sentences are not entirely equivalent. Basque grammars make abundant use of the concept of galdegaia 'what is asked'. The sentences (3) and (6) are answers to the question Non dago Jon? 'Where is Jon?', so the most important component of the answer is etxean 'home/at home', which is thus located in a pre-verbal position. If the question would be answered in one word, the word would be etxean 'at home.' The sentences (4) and (5) answer the question Nor dago extean? 'Who is at home?'. The answer to that question is clearly Jon, which is, therefore, located in a pre-verbal position. In Lambrecht's (1994) classification of focus types, this 
focus closely resembles Argument Focus, in which the focus construction has a clear and transparent meaning in identifying the referent and providing a missing entity in a given situation. Because of this focus position, Basque has been seen as a language with transparent pragmatics. Bellver and Michaelis (1999), however, argue that the one-to-one relationship between a preverbal syntactic position and focal scope is not as clear as previously thought, and that the pre-verbal position cannot be explained in terms of left-movement. They suggest that the preverbal position in Basque acts mostly like a prosodic peak in English, and propose the preferred clause structure as a criterion that syntactic analyses must meet in order to have a sound empirical basis.

Coming back to the examples above, despite all the possible variants of the word order (b-e), it is noteworthy that none of the sentences above begins with the verb dago 'is, there is'. According to Trask (1997: 109), because of the preverbal position of galdegaia 'what is asked', a finite verb cannot occur in a sentence-initial position in Basque, unless it is a periphrastic verb. ${ }^{2}$

\subsection{Word Order of Predicative Constructions in Spanish}

Leonetti (2015: 1) notes that the research on Spanish copular sentences has not considered word order in detail. The unmarked word order of Spanish predicative constructions is Svx. vxs and vsx are possible inversion patterns. The order vsx is only possible with the copula verb estar, 'to be (temporary)', whereas this order is anomalous with the copula verb ser, 'to be (permanent)' (Leonetti, 2015). Examples 7 and 8 are from Leonetti (2015).

$\begin{array}{lll}\text { José } & \text { es } & \underline{\text { bombero. }} \\ \mathrm{S} & \mathrm{V} & \mathrm{X} \\ \text { José } & \text { COP } & \text { fireman } \\ \text { 'José is a fireman.' } & & \end{array}$

vxs is a possible inversion pattern.

$\begin{array}{lll}\text { Es } & \text { maja } & \text { la chica } \\ \mathrm{V} & \mathrm{X} & \mathrm{S} \\ \mathrm{COP} & \text { nice } & \text { the girl }\end{array}$

'The girl is nice.'

2 Actual language use is at cross-purposes with this general rule, at least in the historical written documents (Hidalgo, 1995): verb-initial copular sentences were abundantly used in the Basque texts between the 17 th and the 2oth century, particularly in cases where they are responses to questions. This word order, however, seemed to become less common when approaching the modern times. 
Both in the canonical word order svx and the inversion pattern vxs the predicative is realized post-verbally (as well as in the other possible inversion pattern vSx). These patterns are in direct contrast with the previously examined Basque predicative constructions, in which the predicative element is always described to be in a pre-verbal position.

Dominguez (2002), in her description of focus in Catalan and Spanish, notes that Spanish is subject to the nuclear stress rule, according to which the intonational prominence (focus) is located in the rightmost position of a clause. Stress shift is not an available option for focus marking in Spanish, so the word order changes for the focused element to receive stress, and, through stress, syntactic prominence. The following examples (9-12) from Dominguez (2002) illustrate this phenomenon.

(9)

$\begin{array}{lll}\text { Tu padre } & \text { vino } & \text { ayer. } \\ \text { S } & \text { V } & \text { PP } \\ \text { your father } & \text { arrive; PST } & \text { yesterday }\end{array}$

'Your father arrived yesterday.'

$(10)$

$\begin{array}{lll}\text { Vino } & \text { tupadre } & \text { ayer. } \\ \text { V } & \text { S } & \text { PP } \\ \text { Arrived } & \text { your father } & \text { yesterday }\end{array}$

(11) Vino ayer tupadre. V PP $\quad S$

Arrived yesterday your father

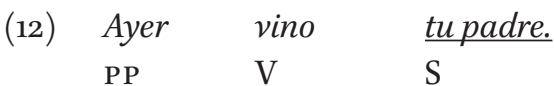

Yesterday arrived your father

The underlined elements carry focus and stress. They are all located in the rightmost position. Changing the word order to put different parts of the sentence into focus does not change the fact that the focused constituent is, contrary to Basque, located in a post-verbal position. Nevertheless, the role of prosody and stress in Spanish focus constructions is important information considering the interpretation of the results of this study. 


\section{The Study}

\subsection{Data}

The examples of monolingual Basque constructions and bilingual BasqueSpanish constructions are examined in two types of conversational data. Dataset one is a bilingual dataset. Twenty-two hours of conversational data with twenty-two Basque bilinguals were gathered to examine Basque-Spanish code-switching. In order to do this, the data were gathered in informal circumstances, such as in bars and at dinner tables, and only the parts that contained code-switching were transcribed. This is why the monolingual sentences must be examined in a different set of data. Dataset two consists of semi-structured interviews where the speakers were discussing code-switching and were therefore very conscious of it. This led to the avoidance of code-switching in dataset two, which is mostly, though not entirely, monolingual. Eight hours of this data with twenty-eight bilinguals have been transcribed in its entirety.

The largely monolingual dataset two contained 304 monolingual Basque predicative constructions with the copula $d a$. The bilingual predicative constructions with Spanish predicative elements were 103 in number, and 87 of them were found in the bilingual dataset, whereas 16 bilingual predicative constructions were found in the "monolingual" dataset one.

The data were collected in the Greater Bilbao area of Biscay, Basque Autonomous Community. The age range of the language consultants was from nineteen to fifty-seven. The participants were recruited through the researcher's social networks. They represented different professional groups and had diverse sociolinguistic backgrounds.

\subsection{General Results}

Table 1 presents the distribution of the word orders of the monolingual and bilingual predicative constructions with the third person singular copula verb $d a(i z a n)$ in the analysed data.

As shown in Table 1, of the 304 Basque monolingual predicative constructions, 245 instances follow the word order XV; 59 constructions exhibit the

TABLE 1 The word order of the predicative constructions with the copula $d a$ in the data

\begin{tabular}{lrrc}
\hline & $\mathbf{X V}$ & $\mathbf{V X}$ & Total \\
\hline Monolingual & 245 & 59 & 304 \\
Bilingual & 21 & 82 & 103 \\
\hline
\end{tabular}


word order vx. Of the 103 bilingual predicative constructions, 82 follow the word order vX and 21 constructions have the word order XV.

When we compare the word orders of the monolingual and bilingual constructions from the data with the grammatical descriptions of the predicative constructions as outlined in section 2, Basque: PREDICATIVE ELEMENT + COPULA and Spanish: COPULA + PREDICATIVE ELEMENT, we can see that $81 \%$ of the monolingual Basque constructions follow the canonical Basque word order, whereas $80 \%$ of the bilingual constructions, consisting of the Basque copula $d a$ and a Spanish predicative, follow the Spanish word order. The difference in the word order patterns is highly significant, ${ }^{2}(1$, $\mathrm{N}=407)=123.15, p<.001$.

In the following two subsections ( 3.3 and 3.4 ), I will describe both the monolingual and the bilingual predicative constructions found in the data in more detail. In subsection 3.5, I will break down and analyse the distribution of the word orders according to the sociolinguistic background of the bilingual speakers.

\subsection{Monolingual Basque Predicative Constructions}

Table 1 shows that most instances of the monolingual predicative constructions with the copula $d a$ follow the canonical Basque word order Xv. The following examples of monolingual predicative constructions found in the data are classified under several subgroups to give the reader an idea about the variety of different types of predicative constructions found in the data. The structurally simple examples are discussed first to show how the predicative structures generally behave in the data. Then the more complex examples of predicative constructions will be discussed to highlight the fact that the tendencies are maintained also in a more complicated syntactic environment. Finally, the counterexamples to the general tendency will be discussed along with the reasons, such as the interplay of different monolingual and bilingual constructions, why they go against the tendency. Examining predicative constructions in different types of syntactic environments gives us an insight into the organisation of the constructions in bilingual speakers' cognitive representation.

\subsubsection{Simple Predicative Structures}

The next two examples show cases of simple predicative constructions with a Basque noun or noun phrase as the predicative element. 
(13) Bere erritmoa

bere erritmo-a

osoona da.

her rhythm-DET

oso on-a da

'She's got a very good rhythm.'

(14)

$\begin{array}{lll}\text { Normalagoa } & d a & \text { munduan. } \\ \text { normal-ago-a } & \text { da } & \text { mundu-a-n } \\ \text { normal-COMPAR-DET } & \text { COP } & \text { world-DET-INESS }\end{array}$

'It's more normal in the world.'

In both examples, an adjectival predicative precedes the copula verb. (13) follows the canonical Basque word order of the predicative construction, in which a noun phrase subject bere erritmoa 'his rhythm' is followed by the predicative adjectival phrase oso ona 'very good', and the copula verb is located in the rightmost position. (2) also follows the Basque canonical word order. Note that Basque, like Spanish, is a pro-drop language, i.e., no pronoun is required for 'it/that' in sentences such as (14). The predicative normalagoa 'more normal', is located in a pre-verbal position, whereas the PP munduan, 'in the world' is placed after the verb. The PP could also be located at the beginning of the sentence, i.e., munduan normalagoa da 'it is more normal in the world', but as the word munduan is not the focus of the sentence, its position does not have syntactic or semantic relevance regarding the word order of predicative constructions.

As noted earlier, the language contact situation in the Basque Country has lasted for two thousand years. This is visible in loan words such as erritmoa, normalagoa and munduan. In (2), the predicative normalagoa carries both the Basque comparative -ago and the Basque general determiner - $a$, so the word is completely integrated into Basque also from a morphosyntactic point of view. These lexical items appear in Basque dictionaries such as Elhuyar (2000), and are considered established loans. The constructions, therefore, can be considered monolingual.

\subsubsection{Complex Relative Structures}

In (15), the predicative structure is rather simple, but the subject is a longer constituent subsuming a relative clause. Such heavy nominal structures are often located in a post-verbal position in Basque, yet the word order in this example is SXV. 
(15) Eta normalean garailea, ateratzen dena,

eta normal-ean garaile-a atera-tzen d-en-a

and normal.INESS winner.DET come.out-IMPF AUX.INTR-REL-DET

gaztelania da.

gaztelania da.

Spanish COP

'And usually the winner, the one that comes out, is Spanish.'3

The predicative can also be a subordinate phrase construction, a syntactical nominalization with the general determiner $-a$ that is added to the finite verb. In (16), the determiner is added to the relativized auxiliary zait $+(a)$ $n+a>$ zaidan. The predicative construction is heavy, yet neatly follows the Basque canonical order XV. The subject pronoun hau/hori/hura, 'this/that/ that' is dropped.
(16) $\underline{\text { Niri }} \underline{\text { beti }}$

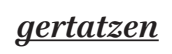
zaidana
da.
ni-ri beti
gerta-tzen
zai-da-n-a
da.
Me-DAT Always happen-IPFV
AUX.ABS.SG3-DAT.SG1-REL-DET COP
'That's what always happens to me.'

\subsubsection{Counterexamples}

As shown in Table 1, most of the monolingual constructions follow the Basque word order. There are, however, some monolingual constructions in which the word order is vx. The word order vx appears in 19\% of the occurrences of monolingual predicative constructions, and the reasons for a post-verbal predicative are worth examining.

In (17), the copula verb precedes a heavy predicative structure. Here $d a$ seems to have an introductory function of 'it is that', 'that is', even 'I mean'. In these contexts, $d a$ is often pronounced in an emphatic manner, so that the interlocutor anticipates an explanation. An introductory $d a$ appears 14 times in the data with the vx word order, not even once with a XV word order.

$\begin{array}{lllll}\text { (17) } & \text { Eta } & \text { gauzatxo bat esan nahi dut } & \text { eta da } \\ \text { Eta } & \text { gauza-txo bat esan nahi du-t } & \text { eta da } \\ \text { And } & \text { thing.DIM one say want AUX.TR.3SG-ERG.1SG and cop }\end{array}$

3 As an interesting side note related to the topic of this article, this is an illustrative example from the metalinguistic conversations of dataset two: the speaker is talking about the language contact situation in the Basque Country. He sees Spanish as the clearly dominant language of the area and, therefore, the language that seems to "win" both as the chosen medium of interaction in everyday life, and in the bilingual speaker's mind. 


\begin{tabular}{|c|c|c|}
\hline lehengoak & hamar hitzetik & zazpi egiten \\
\hline lehengo-a-k & hamar hitz-etik & zazpi egi-ten \\
\hline first-DET-ERG & ten word-ABL & seven make-IPFV \\
\hline ditu & & euskaraz \\
\hline d-it-u & & euskara-z \\
\hline AUX.TR-ABS. $3 \mathrm{I}$ & L-ERG.3SG & Basque-INSTR \\
\hline
\end{tabular}

'And I want to say one little thing and it is the first one says seven out of ten words in Basque.'

In (17) both the heavy structure of the predicative, which includes a complete sentence "the first one says seven out of ten words in Spanish", and the explanatory/introductory function of $d a$ are likely to influence the post-verbal position of the predicative. These factors together strengthen the speaker's choice to place it in the rightmost position. The heavy structure is easier to process when placed in the final position of the utterance. When $d a$ is used in an introductory function, the copula is positioned before the predicative structure. The introductory function of $d a$ seems to have conventionalized, and seems to constitute a mini-construction (Boas, 2003) on its own.

In (18), the predicative Mikel is located in a post-copula position, which does not follow the Basque word order for predicative constructions. It also goes against the grammatical constraint mentioned by Trask (1997: 109): a finite verb cannot occur in a sentence-initial position, unless it is a periphrastic verb. In this example, we can assume that the sentence structure is modelled on the equivalent Spanish construction es Mikel 'it is Mikel', with a typical sentence-initial copula.

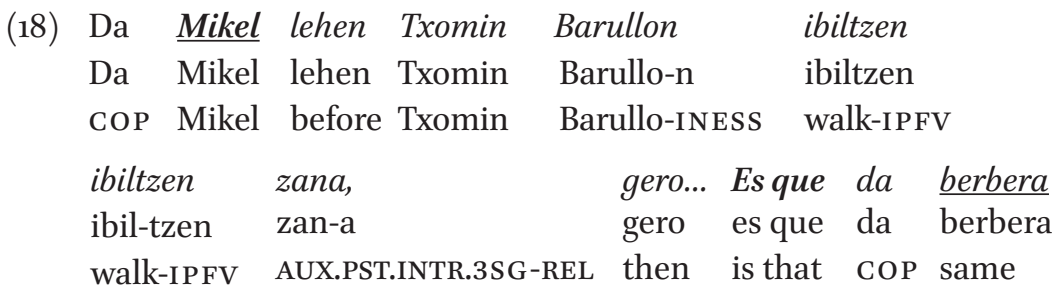

'That's Mikel, the one who used to hang out at Txomin Barullo, then... It's that he's the same.'

The predicative is also placed after the copula verb in the following clause. The Spanish discourse particle es que 'it's that', which opens the clause, may have triggered this choice of the word order pattern. Another possible trigger for the second-clause word order is priming: the recent activation of the word order 
vx in the first predicative construction makes the vx word order easily accessible to the speaker for the second predicative construction.

In both (17) and (18), several different factors might trigger the vx word order, both contact-induced and language-internal. These motivations for language change and variation are not mutually exclusive, and multiple causation (Thomason, 2001) cannot be ruled out, as contact-induced and language-internal motivations both contribute to the choice of one type of construction over another.

\subsection{Bilingual Basque-Spanish Predicative Constructions}

Compared to the patterns observed in the monolingual data, bilingual constructions behave differently. Of the 103 identified bilingual predicative constructions that consist of Basque copula and a Spanish predicative, 82 $(\sim 80 \%)$ constructions follow the Spanish word order, with the predicative element placed after the verb. In other words, when a Spanish predicative is inserted, the Basque word order changes to the Spanish word order. Let us consider some examples following the categorization of Section 3.3: from simple predicative structures via complex predicative structures to the counterexamples. The Spanish elements in the examples are bolded.

3.4.1 Simple Predicative Structures

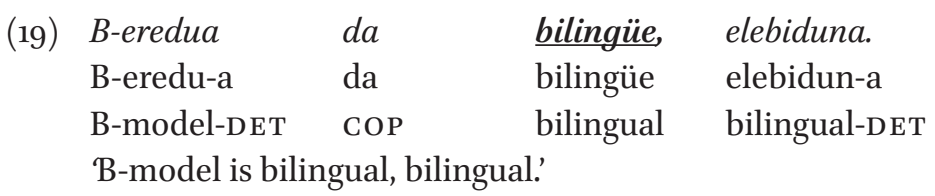

$\begin{array}{llllll}\text { (20) Eta } & \text { Gorka }^{4} & \text { adibidez, } & \text { Gorka } & \text { da } & \text { chungo. } \\ \text { Eta } & \text { Gorka } & \text { adibide-z } & \text { Gorka } & \text { da } & \text { chungo } \\ \text { And } & \text { Gorka } & \text { example-INstr } & \text { Gorka } & \text { cop } & \text { difficult } \\ \text { 'And Gorka, for example, Gorka is difficult.' } & & \end{array}$

In (19), the speaker is describing the language models used in the educational system in the Basque Country. He inserts the Spanish word bilingüe, 'bilingual', after the Basque copula $d a$, then gives the Basque equivalent elebiduna. The word order follows the Spanish model svx. In (20), the speaker uses the Spanish colloquial expression chungo 'difficult' to describe his friend.

Here the Spanish predicatives bilingüe and chungo do not take the word-final Basque determiner - $a$, so they are not integrated into the Basque morphosyntactic structure.

4 Names changed. 


\subsubsection{Basque Elements in the Predicative Noun Phrase}

The inserted predicative structure may contain Basque elements. In (21), the speaker is describing the organization of the supporters of the football club Athletic Bilbao and uses the Spanish word, tesorero 'treasurer', in an otherwise Basque construction. Despite the Basque locative -ko that precedes the Spanish word, the word order follows the Spanish word order svx. The speaker seems to flag his switch with a hesitation marker after the insertion.

$\begin{array}{lllll}\text { (21) Jon da } & \underline{\text { Peñako }} & \text { tesorero, } & \text { edo } \\ \text { Jon da } & \text { Peña-ko } & \text { tesorero } & \text { edo } \\ \text { Jon cop } & \text { Peña-LOC } & \text { Treasurer } & \text { or } \\ \text { 'Jon is the treasurer of the club, or...' } & \end{array}$

In this insertion, the first part of the PP is in Basque, as the Basque locative genitive -ko and not the Spanish preposition de is used to connect the elements of the PP construction, peñako tesorero vs. tesorero de la peña. The word peña 'supporter/ fan club' is used in both Basque and Spanish. The noun peña is inserted into to a Basque adposition construction and takes the case marker -ko. However, tesorero lacks the Basque word-final determiner $-a$, required by the adposition construction, and the predicative construction follows the Spanish word order svx. Thus, tesorero is not entirely integrated into a Basque morphosyntactic structure.

\subsubsection{Predicative Structure with a Complex Copula}

Predicative structures also appear in subordinate clauses. Basque subordinate structures are often marked with a suffix attached to the finite verb. In the example below, the causative suffix (-e)lako is attached to the copula $d a$, i.e., $d a+-(e)$ lako $>$ delako.

$\begin{array}{lllllll}\text { (22) } & \text { Ez dakit, } & \text { delako } & \underline{l a} & \text { duquesa } & \text { del } & \text { Alba. } \\ \text { Ez daki-t } & \text { d-elako } & \text { la } & \text { duquesa } & \text { de-l } & \text { Alba. } \\ \text { NEG } & \text { know.3SG-1SG } & \text { COP-CAUs } & \text { the duchess } & \text { of-DET } & \text { Alba } \\ \text { 'I don't know, because she is the duchess of Alba.' } & & \end{array}$

The copula delako 'because (she) is' and the predicative la duquesa del Alba in (10) are located in a subordinate, causative clause. The complexity of the copular verb does not seem to affect the tendency observed in the data. The word order here, as in the vast majority of cases involving Spanish predicatives, is vx. The predicative in this example is placed in the final position: the predicative is relatively heavy, and the speakers might have an urge to group all the Basque elements together to facilitate the processing of the two languages at 
the same time. The Spanish predicative is inserted in a position where it does not interfere with the otherwise Basque elements, thus making back and forth switching unnecessary.

\subsubsection{Contrastive Focus}

Some of the predicative constructions observed in the data have a strong contrastive element, meaning 'not this, but that'. In (23), the speaker is describing a bull tattoo spotted in a bar. The interlocutor suggests that the person might have the tattoo due to his Spanish-nationalist right-wing ideologies, represented by the Spanish conservative party Partido Popular, $P P$, a claim that the speaker does not accept. According to her, the bull tattoo is a sign of being lower class, not of right-wing tendencies, so she contrasts these two categories in her response.

\begin{tabular}{|c|c|c|c|c|}
\hline Hori ez & $d a$ & PPkoa & $d a$ & barriobajeroa. \\
\hline hori & da & PP-ko-a & da & barriobajero-a. \\
\hline neg & $\mathrm{COP}$ & PP-LOC-DET that & is & lower.class-DET \\
\hline
\end{tabular}

Interestingly, the urge to locate the Spanish predicative in a post-verbal position even overrides the need for a contrastive Basque focus. In the case of an emphatic focus position, one would assume that the Basque galdegaia 'what is asked', were located right before the verb to emphasize the contrastive effect and to give the contrast more prominence. However, this is not the case, and even though the word barriobajeroa 'lower class' is meant to contrast with PPkoa 'PP-like', the bilingual construction follows the Spanish model vx. Adding the Basque determiner $-a$ at the end of the Spanish adjective barriobajero does not evoke the need for the canonical Basque word order (Hori barriobajeroa $d a$ ) of the predicative construction. The Spanish order is preferred even in a case that requires a stronger emphasis on the focus.

\subsubsection{Counterexamples}

Even though the tendency for bilingual predicative constructions to follow the Spanish word order pattern is conspicuous - they comprise $8 \circ \%$ of the examples found in the data - there is some variation. In other words, as in the case of monolingual predicative constructions, there are bilingual constructions that deviate from the identified trend. Twenty-one bilingual predicative constructions found in the data follow the Basque word order pattern (S)XV. The low number of counterexamples testifies to the enormous influence of Romance grammar on Basque in general. It is also worth noting that more than half of these counterexamples 
involve other constructions that explain the deviations from the tendency. The following examples highlight the interplay of the bilingual and monolingual constructions in the everyday bilingual speech.

In (24), the Basque predicative construction is preceded by an object clause. Note that in the preceding object clause the speaker inserts a Spanish noun phrase as the object and uses the Spanish (s)vx word order. In the predicative construction, however, Spanish adjective maja 'nice, pleasant' is inserted in a Basque predicative construction without any change in the Basque XV word order.

(24) Gaur bisitatu dut
gaur bisitatu du-t

The Basque quantitative oso 'very' might help to maintain the unity of the Basque construction, so that the whole construction is perceived as essentially Basque despite the Spanish insertion. The word order XV occurs in three other constructions with Spanish predicatives preceded by oso. No instances of [ $d a$ oso PREDICATIVE] are found among the 42 monolingual and bilingual predicative constructions with oso in the data. ${ }^{5}$ The Basque speakers seem to treat the construction [oso PREDICATIVE $d a$ ] as a construction with a fixed word order. Apparently, the insertion of a Spanish adjective does not influence this word order.

Of the twenty-one bilingual predicative constructions that follow the Basque word order $\mathrm{XV}$, nine are replications of the Spanish construction [es + ARTICLE + N], for example es una chorrada/pasada/putada/la hostia, lit. 'it is a stupidity/an exaggeration/a shame/awesome, etc.' These constructions express stance and pertain to the colloquial register. In their bilingual form they present considerable variation of word order even in the speech of the same speaker. The predicative element of these colloquial constructions is always a Spanish noun, but apart from that they are reproduced in the data in all possible combinations, such as the following examples with the Spanish colloquialisms hostia and pasada. The constructions that are reproduced here are [es la hostia] and [es una pasada]. The Spanish unstressed definite article la merges with the following word hostia to form a chunk, whereas the indefinite article una is stressed and often translated by the Basque indefinite article bat.

5 There is one case of svx word order in a bilingual predicative construction with the copula verb izan in the second person singular, zu zara oso guay 'you are very cool'. 
(25) Spanish word order, Spanish article.

$\begin{array}{lll}\text { Da } & \underline{\text { la }} & \underline{\text { hostia. }} \\ \text { is } & \text { DET } & \text { host, communion wafer }\end{array}$

'That's crazy/awesome.'

Spanish word order, Basque article.

Da pasada bat.

is exaggeration ONE/INDET

'That's incredible.'

Basque word order, Spanish article.

Gari $\underline{\text { la }} \quad \underline{\text { hostia }} \quad d a$

Gari DET.FEM communion wafer is.

'Gari is crazy/awesome.'

Basque word order, Basque article.

$\begin{array}{lllll}\text { Pasada } & \underline{\boldsymbol{b a t}} & d a, & \text { pasada } & \text { bat. } \\ \text { Exaggeration } & \mathrm{ONE} / \text { INDET is, } & \text { exaggeration } & \text { ONE/INDET. }\end{array}$

'That's incredible, incredible.'

All possible combinations of the originally Spanish construction [es ART N] with the copula $d a$ are given in (25). Nine bilingual constructions follow the Basque word order, and fourteen follow the Spanish word order vx. These recurrent bilingual constructions could be characterized as partial loan translations of the Spanish construction. They are based on chunks that are memorised and activated as a whole (Backus, 2003). The Spanish noun lexemes within them frequently occur in conventionalized code-switching. For example, the word pasada alone appears 19 times in the data (not only in predicative constructions). These Spanish colloquialisms show a higher degree of integration into the Basque lexicon than those Spanish predicatives that are unique occurrences of a code-switched word. The conventionalization, in turn, is likely to strengthen the tendency to follow the Basque word order pattern. Nevertheless, the variation observed here shows that a possible conventionalization process is likely to be ongoing, not fully accomplished. Due to their frequency in colloquial speech, the underlying Spanish chunks are highly entrenched in the speaker's mental lexicogrammar. This may influence their stability in terms of the Spanish word order pattern and slow the generalization of the Basque word order pattern. 


\subsection{L1 and L2 Basque Speakers: an (Un)expected Difference}

In addition to the grammatical factors that affect the placement of the predicative, there is a sociolinguistic factor that seems to affect the distribution of XV and vX word orders in the data: the speaker's linguistic biography. Until the 198 os most bilinguals in the Basque Country had a Basque-speaking family background and few Spanish speakers learned Basque. However, during the last forty years, the numbers of Basque speakers who have Spanish as their L1 have risen considerably, and in city areas such as the Greater Bilbao district they now outnumber native Basque speakers (Basque Government, 20og: 72). In the Basque Country these speaker groups are usually referred to as euskaldun zaharrak 'old Basque speakers', and euskaldun berriak 'new Basque speakers'. A prototypical old Basque speaker acquires the language at home, whereas a new Basque speaker learns the language through formal education. Among the language consultants in this study, 24 are L1, or old, Basque speakers and 26 are L2, or new, Basque speakers.

The direction of the variable is unpredictable before looking at the numbers. On the one hand, the L2 Basque speakers might model the predicative structures on their L1, Spanish. On the other hand, research investigating code-switching practices of Basque-Spanish bilinguals has shown that the L2 Basque speakers tend to keep their languages more separate than the Li Basque speakers who learn both languages in informal contexts in the bilingual community. The Li Basque speakers tend to use their linguistic repertoire more as a whole, and they use more intensive code-switching than the L2 Basque speakers (Lantto, 2012). Therefore, the L2 speakers might also favour the more normative options in this case. Of course, this variable might also be expected to show no difference at all; Larrañaga and Guijarro-Fuentes (2013), for example, found no differences in copula choices in Basque-dominant children and L2 Basque learners.

Table 2 shows the use of the different word orders in monolingual predicative constructions against the pattern of acquisition of Basque. Both groups of speakers favour the Basque word order for monolingual constructions. The difference between the groups is not significant, $\chi^{2}(1, \mathrm{~N}=304)=0,98, p=0.322$.

Table 3 shows the use of the different word orders in bilingual predicative constructions against the pattern of acquisition of Basque. We can see that while the L2 Basque speakers slightly favour the Spanish word order in bilingual predicative constructions, i.e., [da PREDICATIVE], the Li Basque speakers strongly favour the Spanish word order in such constructions. The difference in word order patterns is significant, $\chi^{2}(1, \mathrm{~N}=103)=9.17, p=.002$. On the whole, the L1 Basque speakers produce bilingual predicative constructions at a 
TABLE 2 The word orders of monolingual predicative constructions

\begin{tabular}{|c|c|c|c|}
\hline & Li Basque & L2 Basque & \\
\hline $\mathrm{XV}$ & 142 & 103 & 245 \\
\hline \multirow[t]{2}{*}{$\mathrm{VX}$} & 30 & 29 & 59 \\
\hline & & Total & 304 \\
\hline \multirow[t]{2}{*}{ TABLE 3} & \multicolumn{3}{|c|}{ The word orders of bilingual predicative constructions } \\
\hline & Li Basque & L2 Basque & \\
\hline $\mathrm{XV}$ & 9 & 12 & 21 \\
\hline \multirow[t]{2}{*}{$\mathrm{vX}$} & 63 & 19 & 82 \\
\hline & & Total & 103 \\
\hline
\end{tabular}

far higher rate than the L2 Basque speakers, whereas the occurrences of monolingual predicative constructions are similar in the two groups.

\section{4}

\section{Discussion}

In this article, I have demonstrated that monolingual Basque predicative constructions follow the canonical Basque word order in $\sim 81 \%$ of the cases, whereas bilingual predicative constructions with a Spanish predicative element follow the Spanish word order in approximately $80 \%$ of the occurrences in the data used for this study. There is thus a strong correlation between the monolingual predicative construction with the Basque canonical word order and the bilingual construction with the Spanish word order. Basque-Spanish bilinguals have a cognitive representation of both the Spanish and the Basque predicative constructions. In theory, they could draw on both in a conversation, even when forming predicative constructions without overt Spanish material. The word order of the bilingual sentences, however, suggests that code-switching strengthens the convergence of syntactic structures, even though in a situation of a long-standing language contact and extensive societal bilingualism large, though not all, parts of the linguistic resources are already shared.

\subsection{Why the Choice of Spanish Word Order Pattern?}

In the overwhelming majority of the bilingual constructions, the inserted Spanish predicative determines the word order of the construction. Most of the 
counterexamples to the observed tendencies involve other underlying constructions that affect the placement of the predicative, which highlights the subtle interplay of the monolingual and bilingual constructions both in the speakers' cognitive representation and in their bilingual speech production. In the light of the language contact literature and the context of this particular language contact situation, several factors could be identified that influence the choice of the Spanish word order with a post-verbal predicative. It is not possible to single out only one factor, as they might well all contribute to the general tendency. These are the factors that I would like to highlight in the discussion:

1) Acquisition pattern. The pattern of language acquisition affects the cognitive organization of the constructions in the bilingual mind. When a bilingual learns a language in an environment where hybrid constructions and bilingual mode are not tolerated and the two languages are strictly compartmentalized, she experiences predominantly monolingual constructions and navigates towards more monolingual constructions in her speech. The constructions of the different subsystems labelled "languages" (defined by normative language authorities) are kept more separate than in the minds of the speakers who have become bilinguals in a less regimented environment.

This is seen in the different distributions of the word orders between L1 and L2 Basque speakers. L1 Basque speakers, who generally have more experience of bilingual speech, show a strong preference towards the Spanish word order for bilingual predicative constructions. Among the L2 speakers, the tendency is more restricted. The results are in line with the code-switching research investigating the two groups of Basque speakers (Lantto, 2012). L2 Basque speakers learn the languages mostly in contexts of "double monolingualism" (Jørgensen, 2005), where adhering to monolingual language norms is encouraged and hybridism rejected. They receive continuous input with the Basque canonical word order. When L2 Basque speakers code-switch, it is seen as proof of a low competence in Basque (Lantto, 2016). Due to the classroom environment and the pressure to prove their linguistic competence, they are used to keeping the languages separate and striving to speak 'pure' Basque. This makes them produce Basque variants more often than the Li Basque speakers when they combine elements of their repertoire.

The L1 Basque speakers, in turn, receive more input in the minority language outside the classroom in a bilingual community, where Basque is spoken in a bilingual mode and hybrid constructions are tolerated. Many of them have learned to draw on their language repertoire as a whole. They have experienced constant bilingual speech and bilingual constructions throughout their lives, which results in a greater entrenchment of bilingual constructions in 
their mental lexicon/grammar and in their wider use in their own bilingual speech. In addition, the L1 Basque speakers' language competence in Basque goes unquestioned by the surrounding society. The language authority granted by the native-speaker status allows the native speakers to cross the demarcation boundaries in a way that is not permitted to non-native language speakers (Smith-Christmas and Armstrong, 2014; Lantto, 2016). In this case, the more tolerant attitude towards the hybrid constructions and a richer experience with them manifests in the more frequent use of the Spanish word order patterns in their speech.

2) Social dominance and cognitive representation. Why, then, would the speakers prefer the Spanish word order in the absence of strict social constraints against hybridity? Contact linguistic research has delivered evidence that the socially dominant language tends to influence the socially less dominant language in a greater degree than vice versa. Despite the success of the revitalization efforts in the Basque Country, Basque still remains a minority language. All Basque speakers are bilingual, whereas the Spanish speakers are not. At the moment of interaction in the minority language, there is no need to supress the constructions associated with the majority language, as the interlocutor without exception also understands both languages. The monolingual majority language speakers, however, have less tolerance for lapses into the minority language (Matras, 2009), which lends the majority language the character of "a (more) monolingual code". Spanish influence on Basque is therefore more tolerated than vice versa. As the language consultant in (3) notes, Spanish becomes the "winner".

The tendency of the socially dominant language to take precedence over the less dominant language can also be explained by the factor of frequency. In the province of Biscay, where $30.3 \%$ of the population are classified as Basque speakers and $20.8 \%$ as passive Basque speakers. Basque was found to be used in $9.4 \%$ of the interactions, whereas Spanish was used in $87.4 \%$ (Altuna, 2016). The linguistic items that are used frequently have stronger representations and are easier to access and process (Bybee, 1995; Diessel, 2007; Versloot and Hoekstra, 2016). The bilinguals have both Basque and Spanish predicative constructions in their repertoire. As Spanish is used more, the Spanish construction is repeated more frequently, which leads to a stronger cognitive representation and a deeper entrenchment of this pattern in the bilingual mind. Both frequency and similarity - the analogies that the speakers draw between constructions - contribute to the force of attraction (Versloot and Hoekstra, 2016). The prototypical predicative Spanish and Basque constructions are structurally relatively similar: they consist of a (often dropped pronominal) 
subject, a predicative, and a copula verb. The interlingual analogies are easy to find, and the speakers might establish the equivalence cognitively.

3) Online processing and pragmatic dominance. Placing the Spanish predicative in the final position makes back and forth switching unnecessary and creates linear equivalence. In general, there seems to be a strong tendency for sentence-final code-switching with Spanish in the final position in the Basque Country. Epelde and Oyarçabal (2019) have observed that in both Basque-Spanish and Basque-French code-switching, Spanish and French PP s are usually inserted as embedded language islands located in a post-verbal position, even though according to Basque grammarians this type of constituents should mostly be located before the verb. Aurrekoetxea and Unamuno (2011) observed that, even though in bilingual sentences the subordinated phrase can be both Basque or Spanish, the sentence is usually started in Basque and ended in Spanish or, as they conclude, rephrasing Poplack (1980), euskaraz hasten dut y termino en español which means 'I start in Basque and finish in Spanish'.

The folk linguistic wisdom in the Basque Country often goes that bilinguals switch from Basque to Spanish, in this direction, because it is just "easier". In situations of language contact, the socially dominant language often becomes also the pragmatically dominant language which requires less processing effort. The pragmatically dominant language is "naturally and spontaneously prioritised unless overridden by the selection mechanism" (Matras, 2009: 98). After directing the major processing effort to the first (Basque) part of the utterance, the speaker might have the need to decrease the effort that goes into processing, and "let it go", i.e., switch to the pragmatically dominant language (Spanish). This might contribute to the general tendency of utterance-final code-switching in this particular language contact situation.

4) Prosodic prominence. Dominguez (2002) notes that the focused constituent in Spanish should be located in the rightmost position. Predicative Spanish words and phrases must be inserted at the end of the utterance because only in this position they can carry prosodic prominence and thus convey focus. Based on the analysed data, I suggest that bilingual speakers strongly associate the Spanish focus/predicative element with the rightmost position: the post-verbal position is part of its cognitive representation, which is then activated at the moment of insertion.

\subsection{Significance of the Findings for Language Change and Questions for the Future}

The analysis of Basque monolingual and Basque-Spanish bilingual constructions in a sample representing the speech of 24 L1 and 26 L2 Basque speakers demonstrates that code-switching affects the word order of the predicative 
constructions. However, several questions could not be addressed in this study. The intertwined bilingual and monolingual constructions in the speakers' repertoire affect the placement of the predicative element, as discussed in the counterexamples to the Spanish word order tendency of the bilingual predicative constructions in section 3.4. In these examples, we saw how embedding the Spanish adjectival predicative in the Basque construction [oso PREDICATIVE $d a$ ] helps to counter the tendency of the Spanish word order in bilingual constructions. On the other hand, many replications of the partially schematic Spanish constructions of the stance-taking construction [COPULA ART N] were reproduced with the Basque word order, as the embedded nouns within the replications have a greater degree of conventionalization into the Basque lexicon. However, the extent and dimensions of this interlingual influence are still unexamined. A heavy structure of the predicative element (mentioned in sections $3.3,3.4$ ) is a possible motivation for a post-verbal placement. The degree of conventionalization of the predicative element in constructions that are partially lexically fixed (section 3.4) is another factor that is interesting within the usage-based framework. The pragmatic impact of particular uses of the construction, such as the introductory function that the copula verb has in some cases (3.3), or the contrastive focus function (3.4), should be studied in detail, and the pragmatic functions of both the copula and the prosody of the sentences should be examined more closely. Further study should also examine the effect of word/phrase insertion on the word order of other construction types than the predicative construction, beginning with different types of focus constructions.

The diachronic dimension of word order convergence is particularly relevant from a usage-based perspective. The recurrent insertion of Spanish predicative elements in code-mixing might be a precursor for the direction of language change in the Basque-speaking bilingual communities. The use of bilingual constructions with the word order [ $d a$ PREDICATIVE] might eventually lead to a generalization of the vx word order even in monolingual Basque predicative constructions. If a post-verbal predicative element (in the case of bilingual constructions a Spanish element) is used frequently with a Basque copula, this can lead to a greater conventionalization of a Basque predicative construction with a post-verbal predicative element. This way, the post-verbal predicative would become an entrenched property of the Basque predicative constructions.

Nevertheless, the direction of linguistic change is hard to predict. The canonical word orders of the predicative constructions are still different after the two thousand years that Basque and Spanish have been in contact. The majority of scholars have claimed that the Basque focus structure has transparent 
pragmatics. The transparent meaning of the pre-verbal focus that provides the missing entity has proven to be robust in the face of contact with a dominating language. A linguistic unit, a construction, consist of both form and meaning. Even though at the surface level the interlingual connections of the elements of both Basque and Spanish focus constructions can be easily drawn by the speakers - the subject, the copula verb, the predicative element - the underlying meaning of the constructions is slightly different and therefore, more resistant to change.

The sociolinguistic situation in the Basque Country has also changed. Basque used to lack institutional support, but now the previously strict diglossia - Basque for the farmhouse, Spanish for public affairs - is being replaced by a situation where the languages are spoken in the same spaces. The form of bilingualism is also changing. The native Basque speakers have a higher competence in Spanish than they did before and a large part of the Basque speakers nowadays are L2-Basque speakers. In an unregulated situation, the large numbers of L2-speakers and the high bilingual competence of the L1-speakers might lead to a wider use of Spanish constructions, including their word order. However, as discussed in section 4.1, the presence of Basque standard euskara batua, nowadays taught in schools and broadcast in the media with its purist norms, provides a continuous input of the Basque canonical word order.

\subsection{Concluding Remarks}

As Bybee notes, "grammar is the cognitive organization of one's experience with language (2006: 711)". When using a particular linguistic structure, the speakers rely on all their experience with it from the previous interactions, strengthening its representation and the degree of entrenchment both in their own and in their interlocutor's repertoire. The differences between the word orders of bilingual and monolingual constructions indicate that lexicon and syntax are not separated from one another, but deeply intertwined in the speaker's mind. This is also shown in the counterexamples to the documented tendency: when the Spanish words are inserted in partially schematic multiword units (as in examples 24 and 25), they are analysed as parts of the Basque unit, hence the greater occurrence of the Basque word order. The "loose" Spanish lexical elements, in turn, are connected to the syntactic properties of the Spanish schematic constructions in which they are most commonly used, so they activate these properties. This is an example of how bilingual grammar emerges in the interaction.

Matter and pattern replication have been treated as separate phenomena in language contact research (Matras, 20og: 236). Borrowing and code-switching, for example, are considered to deal with overt linguistic material, whereas loan 
translations and syntactic interferences are usually seen as replication of covert material (Backus and Dorleijn, 2009). Yet in the case of Basque-Spanish predicative constructions these features of linguistic structure are inseparable. Matter replication (the Spanish predicatives inserted into Basque copular sentences) seem to bring along pattern replication (a change in word order) from the donor to the recipient language.

\section{References}

Altuna, Olatz. 2016. Euskara biziberritzen jarraitzeko erronkak. [The challenges in continuing the Basque revitalization]. Euskaltzaindia. http://www.euskaltzaindia. eus/dok/plazaberri/2016/otsaila/eus_biziberritzen_altuna.pdf. Accessed 21 August 2020.

Arregi, Karlos. 2001. Focus and word order in Basque. http://citeseerx.ist.psu.edu/ viewdoc/download?doi=10.1.1.529.9545\&rep=rep1\&type=pdf. Accessed 21 August 2020.

Aurrekoetxea, Gotzon and Unamuno, Lorea. 2011. Perpaus arteko euskara-gaztelania kode-aldaketa. [Intersentential Basque-Spanish code-switching]. Euskalingua, 25-30.

Babel, Anna and Pfänder, Stefan. 2014. Doing copying: Why typology doesn't matter to language speakers. In J. Besters-Dilger et al. (eds.), Congruence in Contact-Induced Language Change: Language Families, Typological Resemblance, and Perceived Similarity, 239-257. Berlin: De Gruyter.

Backus, Ad. 2003. Units in code switching: evidence for multimorphemic elements in the lexicon. Linguistics 41(1): 83-132.

Backus, Ad. 2014. Towards a usage-based account of language change: Implications of contact linguistics for linguistic theory. In Robert Nicolaï (ed.), Questioning Language Contact. Leiden: Brill.

Backus, Ad and Dorleijn, Margreet. 2009. Loan translations versus code-switching. In B. Bullock and A.J. Toribio (eds.), The Cambridge Handbook of Linguistic Codeswitching, 75-93. Cambridge: Cambridge University Press.

Basque Government. 20og. IV Mapa sociolingüístico. [The IV Sociolinguistic Map]. Vitoria-Gasteiz: Servicio Central de las Publicaciones del Gobierno Vasco.

Beckner, Clay; Blythe, Richard; Holland, John; Bybee, Joan; Ellis, Nick; Ke, Jinyun; Larsen-Freeman, Diane and Schoenemann, Tom. 2009. Language is a complex adaptive system: Position paper. Language Learning 59:1-26.

Bellver, Phyllis and Michaelis, Laura. 1999. What is the information structure-syntax interface in Basque? Annual Meeting of the Berkeley Linguistics Society 25 (1), 26-37. 
Boas, Hans Christian. 2003. A constructional approach to resultatives. Standford: CLSI publications.

Bybee, Joan. 1995. Regular morphology and the lexicon. Language and Cognitive Processes 10(5): 425-455.

Bybee, Joan. 2006. From usage to grammar: the mind's response to repetition. Language 82(4): 711-733.

Diessel, Holger. 2007. Frequency effects in language acquisition, language use, and diachronic change. New Ideas in Psychology 25(2): 104-123.

Dominguez, Laura. 2002. Analysing unambiguous narrow focus in Catalan. In Tania Ionin, Heejeong Ko and Andrew Nevins (eds.), The Proceedings of the Second HUMIT Conference. Massachusetts Institute of Technology Working Papers in Linguistics 43: $17-34$.

Elhuyar. 200o. Euskara-gaztelania/gaztelania-euskara hiztegia. [Basque-Spanish/ Spanish-Basque dictionary]. Villatuerta: Lizarra inprimategia.

Epelde, Irantxu and Oyarçabal, Beñat. 2019. Prepositional phrases in French-Basque and Spanish-Basque code-switches. In Irantzu Epelde and Oroitz Jauregi (eds.), Bihotz ahots. M.L. Oñederra irakaslearen omenez, 214-263. University of Basque Country: Zabalduz.

Grosjean, François. 1997. Processing mixed languages: Issues, findings and models. In Annette De Groot and Judith Kroll (eds.), Tutorials in bilingualism: psycholinguistic perspectives, 225-254. Mahwah, NJ: Lawrence Erlbaum Associates.

Hidalgo, Bittor. 1995. Hitzen ordena euskaraz. [The word order in Basque]. Unpublished doctoral dissertation. University of the Basque Country. http://www.euskara. euskadi.net/appcont/tesisDoctoral/PDFak/bittor_hidalgo.pdf. Accessed 21 August 2020.

Hualde, José Ignacio and Ortiz de Urbina, Jon (eds.). 1993. Generative Studies in Basque Linguistics. Amsterdam/Philadelphia:John Benjamins.

Jørgensen, Jens Normann. 2005. Plurilingual Conversation among Bilingual Adolescents. Journal of Pragmatics 37: 391-402.

Lambrecht, Knud. 1994. Information structure and sentence form. Cambridge: Cambridge University Press.

Lantto, Hanna. 2012. Grammatical code-switching patterns of early and late Basque bilinguals. Sociolinguistic Studies 6(1): 21-43.

Lantto, Hanna. 2016. Conversations about code-switching: the contrasting ideologies of purity and authenticity in Basque bilinguals' reactions to bilingual speech. In Leena Kolehmainen and Janne Skaffari (eds.), New Insights into Multilingual Practices in Speech and Writing. Special Issue. Multilingua 35(2), 137-161.

Larrañaga, Pilar and Guijarro-Fuents, Pedro. 2013. The acquisition of copula verbs in Basque by bilinguals. International Journal of Bilingualism 17(3): 284-308. 
Leonetti, Manuel. 2015. On word order in Spanish copular sentences. In Isabel PérezJiménez, Manuel Leonetti and Silvia Gumiel-Molina (eds.), New perspectives on the study of Ser and Estar, 203-236. Issues in Hispanic and Lusophone Linguistics 5 . Amsterdam: John Benjamins.

Matras, Yaron. 20o9. Language Contact. Cambridge: Cambridge University Press.

Poplack, Shana. 1980. Sometimes I'll start a sentence in Spanish y termino en español: toward a typology of code-switching. Linguistics 18: 581-618.

Riionheimo, Helka and Frick, Maria. 2014. Emergence of Finnish-Estonian bilingual constructions in two contact settings. Sociolinguistic Studies 8(3): 409-447.

Smith-Christmas, Cassie and Armstrong, Timothy Currie. 2014. Complementary reversing language shift strategies in education: the importance of adult heritage learners of threatened minority languages. Current Issues in Language Planning $15(3): 312-326$.

Thomason, Sarah. 2001. Language contact: An introduction. Georgetown University Press.

Trask, Robert Lawrence. 1997. The History of Basque. London: Routledge.

Versloot, Arjen P. and Hoekstra, Eric. 2016. Attraction between words as a function of frequency and representational distance: Words in the bilingual brain. Linguistics 54(6): 1223-1240.

Zubiri, Ilari and Zubiri, Entzi. 200o. Euskal gramatika osoa. [The whole Basque grammar]. Bilbo: Didaktiker, sA. 